\section{Rare presentation of neurofibromatosis and Turner syndrome in a pediatric patient}

\author{
Natalie Gengel, Ian Marshall \\ Department of Pediatrics, Rutgers- \\ Robert Wood Johnson Medical School, \\ New Brunswick, NJ, USA
}

\begin{abstract}
Neurofibromatosis type 1 (NF1) is classically defined by the presence of multiple café-au-lait macules as one of the diagnostic criteria. Turner syndrome (TS) can also present with café-au-lait macules along with short stature. Our patient is the fifth reported with both NF1 and TS and the first who has been on growth hormone for short stature associated with TS.
\end{abstract}

\section{Introduction}

Solitary café-au-lait macules are common birthmarks, ${ }^{1}$ which can vary in color from light to dark brown, with borders that can be smooth or irregular. When multiple café-au-lait macules are present, neurofibromatosis type 1 (NF1) should be considered. NF1 is an autosomal dominant disorder due to loss-of-function mutations in the tumor suppressor NF1 gene (neurofibromin 1). ${ }^{2}$ The worldwide incidence of NF1 is estimated to be 1 in 2500 to 3000 individuals. ${ }^{3,4}$ It is a clinical diagnosis based on the presence of at least 2 of 7 diagnostic criteria. 5 One of the 7 criteria include 6 or more café-au-lait macules $\geq 5 \mathrm{~mm}$ in diameter in pre pubertal, and $\geq 15 \mathrm{~mm}$ in post pubertal children. 5

Turner syndrome (TS) can also present with café-au-lait macules. ${ }^{6}$ TS occurs due to loss of either all or part of the X chromosome, with an incidence of at least 1 in 2500 live births. ${ }^{7}$

Four patients with overlapping phenotypic features of both NF1 and TS have been previously reported. ${ }^{8-10}$ We report the fifth girl diagnosed with NF1 and TS who presented with café-au-lait macules.

\section{Case Report}

An 8-year-old female presented to our clinic for continued evaluation of short stature due to TS. She had been diagnosed with TS when chromosome analysis at age 6 for short stature revealed 45X karyotype (Universidad Autónoma de Santo Domingo,
Dominican Republic). She was started on growth hormone $(\mathrm{GH})$ therapy to promote linear growth. Initially 3 café-au-lait macules were reported on clinical examination. At age 8 years, a clinical diagnosis of NF1 was made based on presence of more than 6 café-au-lait macules measuring $>5 \mathrm{~mm}$ in diameter, axillary freckling, and Lisch nodules on ophthalmologic examination. A novel heterozygous p.M1149V variant of uncertain significance was identified by genetic testing (Center for Human Genetics, Inc., Cambridge, MA, USA). It was predicted that this variant would not be tolerated based on SIFT (http://sift.jvci.org), and probably damaging using Polymorphism Phenotyping v2 (PolyPhen2) (http://genetics.bwh. Harvard.edu/pph2). As the amino acid was conserved amongst species, and p.M1149I variant had been reported as disease causing, it was concluded that p.M1149V variant was likely pathogenic.

\section{Discussion}

NF1 is a RASopathy, a class of developmental disorders caused by germline mutations in genes that regulate the Ras/mitogen-activated protein kinase (MAPK) pathway. ${ }^{11}$ RASopathies produce a group of phenotypically overlapping syndromes, which, in addition to NF1, include Noonan syndrome (NS) and Noonan-like syndrome.11 Another RASopathy called Neurofibromatosis-Noonan syndrome (NFNS), first recognized in 1985 by Allanson et al. ${ }^{12}$ shows phenotypic overlap between NF1 and NS. Although NS and TS share phenotypic similarities, which resulted in patients with NS previously diagnosed with a form of TS, they are distinct genetic conditions. Our patient is the fifth reported with clinical features of both NF1 and TS. Interestingly, the same pathogenic variant, p.M1149V, that was identified in $N F-1$ in our patient has been reported in another patient with NF1,13 who was also diagnosed with mitochondrial complex I deficiency based on investigation for progressive microcephaly. This again was presumed to be coincidental. Our patient was prescribed $\mathrm{GH}$ therapy for the FDA approved indication of short stature due to TS. 14 Short stature, and GH deficiency (GHD) have also been reported as more common in children with NF1 than the general population. ${ }^{15}$ The exact incidence and cause of GHD have not been clearly defined. However, as NF1 has an increased risk for development of benign and malignant tumors, there has been a long-standing concern about the safety of GH therapy in NF1 patients. Review of data from 102 NF1 chil-
Correspondence: Ian Marshall, Department of Pediatrics, Rutgers-Robert Wood Johnson Medical School, 89 French Street, New Brunswick, NJ, 08901, USA.

Tel.: +1.732.235.9378 - Fax: +1.732 .235 .5002$

E-mail: marshaia@rutgers.edu

Key words: Neurofibromatosis type 1; Turner syndrome; Growth hormone.

Contributions: NG, collection of data, and wrote first draft; IM, final revision including discussion.

Conflict of interest: the authors declare no potential conflict of interest

Received for publication: 29 July 2016.

Revision received: 19 January 2017.

Accepted for publication: 28 March 2017.

This work is licensed under a Creative Commons Attribution NonCommercial 4.0 License (CC BY-NC 4.0).

(C) Copyright N. Gengel and I. Marshall, 2017

Licensee PAGEPress, Italy

Pediatric Reports 2017; 9:6810

doi:10.4081/pr.2017.6810

dren on GH therapy ${ }^{16}$ showed the incidence of intracranial tumor occurrence was comparable to that in NF1 patients not treated with GH. ${ }^{17-19}$ Interestingly, in NF1 patients, GH receptor (GHR) expression was identified in plexiform neurofibromas, ${ }^{20}$ which are common precursors of malignant peripheral nerve sheath tumors in NF1.21 Although this does not prove a role of $\mathrm{GH}$ in development of these neurofibromas and a link to malignant transformation, the presence of GHR suggests that these tumors may respond to $\mathrm{GH}$.

\section{Conclusions}

Although the 2 distinct genetic syndromes in our patient are presumably a chance occurrence, it remains important for clinicians to recognize that the presence of one genetic condition that can explain a specific clinical presentation, does not exclude a second. We plan to monitor our patient closely both clinically and biochemically due to the potential risk of malignant transformation of her fibromas on GH therapy.

\section{References}

1. Shah KN. The diagnostic and clinical significance of café-au-lait macules. 
Pediatr Clin North Am 2010;57:113153.

2. Yap YS, McPherson JR, Ong CK, et al. The NF1 gene revisited - from bench to bedside. Oncotarget 2014;5:5873-92.

3. Shen MH, Harper PS, Upadhyaya M. Molecular genetics of neurofibromatosis type 1 (NF1). J. Med. Genet 1996;33:2-17.

4. Williams VC, Lucas J, Babcock MA, et al. Neurofibromatosis type 1 revisited. Pediatrics 2009;123:124-33.

5. NIH. National Institutes of Health Consensus Development Conference Statement: neurofibromatosis. Bethesda, MD, USA, July 13-15, 1987. Neurofibromatosis 1988;1:172-8.

6. Gunther DF, Sybert VP. Lymphatic, tooth, and skin manifestations in Turner syndrome. Int Congress Series 2006; 1298:58-62.

7. Bondy CA. Care of girls and women with Turner syndrome: a guideline of the Turner Syndrome Study Group. J Clin Endocrinol Metab 2007;92:10-25.

8. Schorry E, Lovell A, Milatovich A, Saal H. Ullrich-Turner syndrome and neurofibromatosis 1. Am J Med Genet 1996;66:423-5.

9. Suttur MS, Mysore SR, Krishnamurthy B, Nallur RB. Rare association of turner syndrome with neurofibromatosis type
1 and tuberous sclerosis complex. Indian J Hum Genet 2009; 15:75-7.

10. Hatipoglu N, Kurtoglu S, Kendirci M, et al. Neurofibromatosis type 1 with overlap Turner syndrome and Klinefelter syndrome. J Trop Pediatr 2010;56:69-72.

11. Tidyman WE, Rauen KA. The RASopathies: developmental syndromes of Ras/MAPK pathway dysregulation. Curr Opin Genet Dev 2009;19:230-6.

12. Allanson, JE, Hall, JG, Van Allen, MI. Noonan phenotype associated with neurofibromatosis. Am J Med Genet 1985;21:457-62.

13. Domingues $\mathrm{S}$, Isidoro $\mathrm{L}$, Rocha $\mathrm{D}$, Marques JS. Neurofibromatosis Type 1: a novel NF1 mutation associated with mitochondrial complex I deficiency. Case Rep Genet 2014:423071.

14. Wilson TA, Rose SR, Cohen P, et al. Lawson Wilkins pediatric endocrinology society drug and therapeutics committee: update of guidelines for the use of growth hormone in children: the Lawson Wilkins Pediatric Endocrinology Society Drug and Therapeutics Committee. J Pediatr 2003;143:415-21.

15. Bizzarri C, Bottaro G. Endocrine implications of neurofibromatosis 1 in child- hood. Horm Res Paediatr 2015;83:23241.

16. Howell SJ, Wilton P, Lindberg A, Shalet SM. Growth hormone and neurofibromatosis. Horm Res 2000;53 :70-6.

17. Hochstrasser H, Boltshauser E, Valavanis A. Brain tumors in children with von Recklinghausen neurofibromatosis. Neurofibromatosis 1988;1:233-9.

18. Kuenzle C, Weissert M, Roulet E, et al. Follow-up of optic pathway gliomas in children with neurofibromatosis type 1 . Neuropediatrics 1994 ; 25:295-300

19. Sørensen SA, Mulvihill JJ, Nielsen A. Longterm follow-up of von Recklinghausen neurofibromatosis: survival and malignant neoplasms. N Engl J Med 1986;314:1010-5.

20. Cunha KSG, Barboza EP, da Fonseca EC. Identification of growth hormone receptor in plexiform neurofibromas of patients with neurofibromatosis type 1. Clinics (Sao Paulo) 2008;63: 39-42.

21. Farid M, Demicco EG, Garcia R, et al. Malignant peripheral nerve sheath tumors. Oncologist 2014;19:193-201. 